\title{
El papel desempeñado por los concejos municipales de la República del Ecuador en el reclutamiento de soldados (1830-1860)
}

Marisol Aguilar Echeverría

Universidad de las Fuerzas Armadas, ESPE (Ecuador)

Cristian Rodrigo Espinel López

Universidad de Granada (España) 



\title{
El papel desempeñado por los concejos municipales de la República del Ecuador en el reclutamiento de soldados (1830-1860) ${ }^{1}$
}

\section{The role played by the municipal councils of the Republic of Ecuador in the recruitment of soldiers (1830-1860)}

\author{
Marisol Aguilar Echeverría ${ }^{2}$ \\ Universidad de las Fuerzas Armadas, ESPE (Ecuador) \\ solaguilare@gmail.com
}

Cristian Rodrigo Espinel López ${ }^{3}$

Universidad de Granada (España)

espinelopez@gmail.com

Fecha de recepción: 29 de diciembre de 2020

Fecha de aceptación: 30 de abril de 2021

\begin{abstract}
Resumen
El presente trabajo consiste en concatenar las funciones asignadas a los municipios por parte de la función ejecutiva y legislativa de la república del Ecuador para la dotación de individuos que fueron destinados a reforzar la tropa del Ejército Permanente y así, cumplir objetivos específicos determinados por el gobierno de turno. Este ensayo se basa en el resultado de la indagación de documentos que reposan en archivos históricos, cuya información da cuenta del proceso de recluta por parte de los consejos municipales en base a normativa específica. Esta breve
\end{abstract}

1 Ponencia para presentar en el Simposio de Poder Municipal y regional en América para el XIX Congreso Internacional AEA: Los caminos de América, que debía celebrarse entre el 8 y el 10 de junio del 2021 en Santiago de Compostela.

2 Docente Titular del Departamento de Seguridad y Defensa, Universidad de las Fuerzas Armadas, ESPE. Candidata a doctora en Historia y Estudios Humanísticos, Europa América Arte y Lengua, Universidad Pablo de Olavide, candidata a doctora en el Programa de Doctorado en Ciudad, Territorio y Desarrollo Sustentable, Universidad de Granada.

3 CEO en ELYAE Consultores, Doctor en Historia y Estudios Humanísticos, Europa América Arte y Lengua, Universidad Pablo de Olavide, candidato a doctor en el Programa de Doctorado en Ciudad, Territorio y Desarrollo Sustentable, Universidad de Granada. 
$\underline{\text { El papel desempeñado por los concejos municipales... - M. Aguilar Echevarría }}$

investigación además contempla el rol desempeñado por los cuerpos de milicia en las ciudades como refuerzo a la labor cotidiana de la guardia policial. La institución municipal durante los primeros años de Ecuador como república tuvo una participación decisiva en el proceso de alistamiento de soldados.

Palabras clave: Ejército; Milicias; Municipio; Reclutamiento; Ecuador

\begin{abstract}
The present work tries to link the roles assigned to the municipalities by the executive and legislative functions of the Republic of Ecuador for the provision of individuals who were destined to reinforce the troops of the Permanent Army to meet specific objectives determined by the government in power. This essay is based on the result of the investigation of documents that rest in historical archives, whose information accounts for the recruitment process by the municipal councils based on specific regulations. This brief investigation also considers the role played by the militia corps in the cities as a reinforcement of the daily work of the police guard. The municipal institution during Ecuador's first years as a republic had an important participation in the process of enlisting soldiers.
\end{abstract}

Key Words: Army; Militias; Municipality; Recruitment; Ecuador

\title{
1. INTRODUCGIÓN: LOS INICIOS DE LA RELACIÓN ENTRE MU- NICIPIO Y FUERZA ARMADA DURANTE LOS PRIMEROS AÑOS DEL PERIODO REPUBLICANO
}

La institución municipal ecuatoriana de inicios del periodo republicano constituye uno de los ejes de análisis más sugerentes para interpretar la dinámica de la sociedad de ese tiempo. El municipio, conocido en ese tiempo como cabildo, fue el organismo que aglutinó lo público, lo cotidiano y el funcionamiento de la cultura organizacional que respondió, a su modo, a la realidad de los habitantes circunscritos en entornos geográficos disgregados a lo largo y ancho del estado ecuatoriano. Según el historiador Enrique Ayala Mora, el municipio es concebido como una "gran corporación" que defiende los intereses locales, cuya control y administración estuvo a cargo de la aristocracia avecindada en esos espacios quienes ejercieron presión e influencia en las decisiones políticas, la vida cotidiana de los habitantes, así como también, el manejo de la economía local (Ayala Mora, 2011a, p. 222). Desde esta perspectiva, el analista de este estudio indica que el municipio fue considerado como un centro de poder en que, a más de marcar la pauta en la dinámica del territorio, fue un instrumento de expresión política que permitió la movilización de recursos para llevar a cabo pronunciamientos a favor o en contra de los gobiernos electos constitucionalmente, o que surgieron a raíz de enfrentamientos bélicos que permitieron mandatos de facto (Ayala Mora, 2011a, p. 222)

Con este antecedente, el análisis de la evolución de los municipios ecuatorianos todavía se encuentra en fase preliminar y hasta el momento, no hay suficientes 
estudios que permitan entender los entresijos, complejidades y particularidades de esta institución que, como bien lo apunta José Caño Ortigosa, era la primera figura institucional que representó a la población que gobernaba, ya que era la instancia administrativa que impartió justicia, recaudaba impuestos y proveía de servicios públicos a los vecinos (Caño Ortigosa, 2020).

Este ensayo pretende dar una primera aproximación al tema a través de la información que consta en fuentes primarias. Este análisis consiste en estudiar la injerencia del aparataje y dinámica municipal con el rol de la fuerza armada durante los primeros años del periodo republicano, el cual estuvo concatenado con la labor administrativa y de justicia en esos entornos geográficos. Entre los autores que dieron una primera aproximación a este eje temático antes del periodo republicano fueron Federica Morelli y Santiago Cabrera Hanna. Ambos investigadores coinciden en que el aparato municipal durante la transición de la época colonial al periodo republicano en Ecuador fue objeto de significativas transformaciones que dieron lugar a que este sistema de administración de lo público se limite a gobernar en enclaves dentro del sistema colonial hasta la década de los años veinte del siglo XIX (Morelli, 2011a, pp. 27-47) (Cabrera Hanna, 2021). Consecuencia esa metamorfosis, los cabildos se fragmentaron y dispersaron a raíz de las coyunturas constitucionales e independentistas suscitadas en España y las colonias americanas debido al debilitamiento del régimen monárquico español entre los años 1808 a 1820, así como también la determinación de las élites en tomar las riendas de la administración colonial a pesar de los desacuerdos existentes entre esos clanes con poder e influencia en aquellas jurisdicciones (Rodríguez O., 2006, p. 77-79).

El rumbo que tuvieron las jurisdicciones municipales tras los procesos independentistas, según el análisis Cabrera Hanna, deja entrever que esa instancia de poder pretendió ser debilitada con la implementación de las intendencias en el esquema de administración pública mediante la expedición de la Ley de División Territorial el 23 de junio de 1824 en el cual, se estructuró el espacio territorial del Distrito del Sur (actual república del Ecuador) en departamentos, provincias, cantones y parroquias con el propósito de descentralizar la justicia y las elecciones (Cabrera Hanna, 2021). La instauración de esta forma de organización territorial pretendió mejorar el control de esas jurisdicciones con el apoyo de la fuerza armada cuyos intendentes también hacían las veces de jefes militares mientras cumplieron su función de administradores del territorio en el que residieron (Cabrera Hanna, 2021).

Por otra parte, Cabrera Hanna apunta en su análisis que, al año siguiente de expedida la Ley de División Territorial, apareció otra instancia administrativa superior a la intendencia, esta figura dentro de la administración estatal de la Gran Colombia se denominó Jefatura Provincial y fue creada con el objetivo de canalizar órdenes y demás disposiciones de la instancia central de gobierno, cuyas autoridades que detentaron ese cargo tuvieron en sus manos la administración y la defensa de los departamentos y distritos para así contener posibles intentos conspirativos en 
contra del régimen estatal vigente (Cabrera Hanna, 2021). El autor de este estudio aclara que, tanto la jefatura provincial como la intendencia fueron instancias administrativas que difirieron de la autoridad municipal el cual, actuó como instancia inferior a las anteriores; no obstante, el cabildo tuvo cierto nivel de autonomía en plano económico y de elecciones del poblado en el que se encontraba establecido (Cabrera Hanna, 2021). La figura administrativa de la intendencia desapareció a inicios del periodo republicano, sin embargo, esa instancia intentó de alguna manera controlar el accionar de los regímenes municipales difuminados a nivel nacional, los cuales volvieron a tener poder frente al recién inaugurado aparato gubernamental ecuatoriano. La desaparición de la intendencia permitió que la institución del cabildo vuelva a tener el poder que tuvo desde la implementación de las reformas borbónicas, sin embargo, la fragmentación de ese tipo de institucionalidad atenuó los conflictos entre las élites las cuales no dudaron en armar a los vecinos en caso de amenaza de otro clan que atente a los intereses de esos grupos (Cabrera Hanna, 2021) (Morelli, 2003b, p. 170-176).

En cierto grado, el análisis propuesto por Cabrera Hanna para reconstruir la relación entre la autoridad local con la autoridad gubernamental se basa en el trabajo desarrollado por Morelli, quien afirma que los cabildos, a más de ser autoridades encargadas de la administración de los recursos y defensa de sus intereses, también se encargaron de organizar cuerpos de milicia con el objetivo de servir a la defensa de la patria y la inculcación de valores cívicos (Morelli, 2011a, p. 41-42). El estudio de Morelli además puntualiza que, los alcaldes y funcionarios que ocuparon altos cargos en la administración local también fueron oficiales que comandaron los cuerpos de milicia, quienes constituyeron fuerzas de choque financiados y armados por las élites dispuestas a enfrentarse con las fuerzas del ejército permanente debido a la desconfianza que generaba el accionar del gobierno de turno en contra de los intereses de las élites (Morelli, 2011a, p. 32-33)

A modo de ilustración de lo que pasó durante los primeros años del periodo republicano, Juan Maiguashca indica que la división administrativa del territorio ecuatoriano unificado estuvo en principio dividido en departamentos, provincias, cantones y parroquias y la instancia administrativa más importante fue el departamento en el cual, se dictaminaron decretos ejecutivos para que los gobernadores, corregidores y jefes políticos de cada una de las circunscripciones territoriales (Maiguashca, 1994, p. 361). Posteriormente, la figura del departamento desapareció y se puso en vigencia la existencia de provincias, corregimientos, cantones y parroquias. Bajo ese esquema de la administración pública, entre los años 1830 a 1859 se mantuvieron los cabildos cantonales los cuales se encargaron de elegir a los representantes de los concejos municipales y no en ejercer el gobierno de los municipios como fue antes y esas instancias institucionales se limitaron a obedecer las normas y reglamentos vigentes en esa época (Borrero, 2015, p. 76).

De la documentación primaria consultada en el Archivo Nacional de Ecuador se puede constatar la existencia de sendos decretos ejecutivos y legislativos que 
dispusieron el alistamiento de individuos entre los dieciocho hasta los cincuenta años para defender las fronteras de los ataques procedentes de los estados vecinos y mantener orden en las instituciones del estado en caso de existir sublevaciones.

Debemos tener en cuenta que toda esta institucionalización de la fuerza armada está dividida en dos tipos de formación: la primera es conocida como Ejército Permanente que tiene el carácter de profesional, cuyos miembros se dedicaban exclusivamente a esa actividad y que fue pagada por el estado (Ayala Mora, 2011a, p. 76-78) y según lo dictaminó el artículo 51 de la primera Constitución Política del Ecuador los miembros de la fuerza armada cumplen la misión inalienable de“... defender la independencia de la patria, sostener sus leyes y mantener el orden público" (Georgetown University, s.f.). En este sentido, el carácter de esta formación castrense es obediente con el estado, posición que determina la esencia y razón de ser de las fuerzas armadas ecuatorianas hasta nuestros días. A diferencia del Ejército Permanente, los cuerpos de milicia y la Guardia Nacional son formaciones castrenses conformadas por civiles quienes reforzaron el contingente de los miembros del Ejército Permanente, muchos de esos individuos que conformaron esas formaciones castrenses fueron trabajadores artesanales y pequeños burgueses que estuvieron sujetos a las normativas municipales y legislativas (Prado Arellano, 2019, p. 164).

Es necesario aclarar que los ciudadanos convocados en situaciones de "emergencia nacional" eran procedentes de los cuerpos de milicia y Guardia Nacional, formaciones militares conformadas por civiles que fueron inmediatamente enlistados tras la emisión de un decreto expedido por las autoridades provinciales. La convocatoria de estas formaciones armadas tuvo un componente de lo que en la actualidad conocemos como optimización de recursos debido a que, esas formaciones armadas no eran remuneradas por el estado el cual, no tuvo los recursos financieros suficientes para pagar un estipendio a esas formaciones armadas. Aquellos cuerpos militares formados por ciudadanos fueron reclutados con métodos arbitrarios como la captura y retención forzada de varones sin tener experiencia y formación en los trajines de combate y según la Memoria del Ministerio de Guerra y Marina del año de 1833, los soldados reclutados de esa manera fueron aquellos que eran casados y padres de familia ${ }^{4}$. Todos estos individuos fueron destinados a la tropa que estuvo conformada por artesanos registrados en gremios.

Los cuerpos militares formados por ciudadanos o milicianos fueron auxiliar y urbano y cada una de esas formaciones cumplieron roles diferentes. La milicia auxiliar estuvo compuesta por individuos solteros o casados sin hijos y los que tengan, su número no debió pasar de cuatro ${ }^{5}$. Aquellos sujetos fueron destinados a suplir las bajas del Ejército Permanente al momento de combates de gran

4 Memoria que dirije al Congreso del Ecuador en 1833 el Jeneral Jefe de Estado Mayor Jeneral sobre los negocios de guerra y marina, Imprenta de Gobierno por Juan Campusano, Quito, [p.1]

5 Exposición que dirige al Congreso Constitucional del Ecuador en 1847 el Secretario de Guerra y Marina, Oficina de Joaquín Terán, Quito, p. 10. 
envergadura mientras que los individuos alistados en la milicia urbana se dedicaron a vigilar las ciudades; aquellas formaciones estuvieron conformadas por hombres entre los dieciséis hasta los sesenta años con excepción de los eclesiásticos regulares y seculares, indígenas tributarios, esclavos y aquellos sujetos con enfermedades que no les permitan cumplir con sus funciones.

\section{ACGIONES DE LA INSTITUGIONALIDAD MUNICIPAL AL SER- VICIO DE LAS DEMANDAS DEL EJÉRCITO PERMANENTE}

\subsection{La vigencia del sorteo y del reemplazo como función sustantiva de los concejos municipales}

En el año de 1837 el Ministerio de Guerra y Marina dictaminó el incremento de soldados para el Ejército Permanente a pesar de que ese documento no menciona las razones por las que era necesario el incremento de la fuerza armada. Sin embargo, durante ese año, aquella cartera de estado emitió la Ley Orgánica Militar y la Ley de Conscripción del Ejército normativas enfocadas en regular las formas de reclutamiento y retener a la tropa dentro de las filas castrenses ${ }^{6}$. Así mismo, aquella ley reguló el pago de un salario o prest que iba entre 6 a 8 pesos $^{7}$.

Por otro lado, esta normativa instituyó el sistema del sorteo y del reemplazo. En el primer caso, el sorteo consistió en la selección de individuos para engrosar las filas del Ejército Permanente durante el mes de agosto de cada año, tiempo en el cual los delegados de cada municipio se encargaron de la realización de un acto público el cual fue notificado con días de antelación. Durante el desarrollo de ese evento, los alcaldes y tenientes parroquiales de los pueblos llevaban consigo un libro de alistamientos con la siguiente información al momento del sorteo, la información recogida en esos registros fue: nombres y apellidos del individuo, los nombres y apellidos de sus padres, oficio, estatura, domicilio y condiciones físicas en las que se encontraban.

6 República del Ecuador. Ministerio de Guerra y Marina, Estado y fuerza efectiva del ejército permanente con distinción de la que consta cada cuerpo y el número de clases, en: Memoria que el Ministro de Guerra y Marina presenta a la Lejislatura de 1837, Imprenta de gobierno, por Juan Campuzano, anexo 1.

$7 \quad{ }^{7}$ Ese fue el salario que percibido por los soldados de la tercera compañía del Batallón Ligero No 1, según una de las listas de revista de comisario consultadas para este trabajo, Archivo Histórico del Centro de Estudios Históricos del Ejército/Parcayacu, en adelante AH-CEHE/P, Puertoviejo, enero 7 de 1837, Presupuesto de la paga [integra] de los [señores] oficiales y tropa de la [espresada], Batallón Ligero No 1, 002-Año 1837-1838, f. 8. En el caso de aquellos soldados que percibieron el salario de 6 pesos, se encuentra en una revista de la Compañía de Volteadores del Batallón Ligero No 2, AHCEHE/P, Quito, 7 de enero de 1837, Presupuesto del aber integro que les corresponde a los [señores] oficiales y tropa del presente mes de la fecha, Fondo Administrativo, RC-00005 - RC-00008, Revista de Comisario, Caja 2, RC-00005, Batallón Ligero No 2 del Ecuador, 048 - 1837 - 1844, f. 6. 
En referencia a lo establecido en el artículo 16 de la Ley de Conscripción expedido en 1837, el perfil de los sorteados fue estructurado de la siguiente manera:

..1. Entre los solteros conscriptos, que no sean hijos únicos de viuda, ni de padres ancianos, ni esten cursando estudios, ni empleados de las empresas publicas ni resguardos: ni los que esten dedicados a la agricultura y haciendas de ganado, ni en los aprendices de algun arte u oficio util.

2. Entre los casados sin hijos.

3. Entre los mayores de veinticinco años.

4. Entre los casados con hijos, e hijos únicos de viuda o de padres ancianos, i jovenes que se hallen en la carrera de las letras, i los demás ecceptuados en el primer caso de este articulo que entrarán por el sorteo por el sorteo por su órden, si los primeros no fuesen suficientes para llenar el cupo de reemplazo que corresponda a cada cantón ${ }^{8}$.

Acto seguido, los comisionados encargados de cumplir aquel encargo, ejecutaban el proceso del sorteo según lo establecido en el artículo 6 del reglamento para facilitar la ley de 1837 en que se hacía lo siguiente:

Art. 6.- Se pondrán dentro de una urna tantas bolas negras, cuantos fueren los individuos entre quienes se ha de verificar el sorteo. Dichas bolas se contarán públicamente por el presidente del consejo municipal o por el alcalde o teniente. Luego se extraerán con la misma publicidad tantas bolas negras de la urna, cuantos sean los hombres con que deben concurrir a la parroquia por via de conscripción; i se reemplazaran por cuantas tantas blancas, bien iguales a las negras en su peso i tamaño. Acto continuo, el que haga de escribano llamará por su nombre a cada uno de los parroquianos sujetos al sorteo, para que saque una bola. Si la que sacare fuere negra queda exento por ese año; mas si la sacare blanca, será inscripto su nombre, en el mismo acto i se le intimará que por la suerte le ha tocado servir en el ejercito permanente?

Tras ejecutado ese procedimiento el individuo al que "le tocó la suerte" inmediatamente fue registrado como soldado de leva enrolado en el ejército y evidentemente, al momento de que el individuo fue notificado, muchas veces no recibió esa noticia con agrado sino con preocupación. Tras culminado ese evento, el sorteado estuvo en la obligación de firmar la notificación y en caso de que el "favorecido" no estuviese presente al momento de la transmisión del resultado, este fue remitido a dos personas nombradas por el concejo municipal para que notifiquen al enrolado para que se presente en el lugar donde fue requerido ${ }^{10}$.

$8{ }^{8}$ ANE/Q, Quito, 3 de abril de 1837, Ley de Conscripción del Ejército expedido por el Congreso el 3 de abril de 1837, Fondo Especial, Caja 289, 1837, vol. 718, f. 34.

9 [Decreto Reglamentario del Poder Ejecutivo para facilitar la ejecución de la ley de 1837, sobre la conscripción del ejército permanente]

10 Ibidem. 
La jornada de selección de milicianos terminaba con el registro de los sujetos en un libro cuyo contenido fue enviado al gobernador de la provincia adjuntando una especie de acta que daba cuenta de la realización del sorteo. Al otro día de realizado ese acto público, los individuos sorteados eran dirigidos por un comisionado a la jurisdicción donde eran requeridos. En el caso de los sujetos que evitaron el sorteo fueron encarcelados y procesados penalmente. La vigencia de la práctica del sorteo provocó que los enganchados, en la mayoría de los casos, se convirtieron en prófugos de la justicia, situación que convirtió a aquellos individuos en disidentes de las leyes penales vigentes. Entre las sanciones a los que se vieron avocados aquellos individuos, en caso de que fueran capturados, fue la de cumplir el servicio militar por un tiempo mayor al estipulado por esa ley. Como consecuencia de esta dinámica, la aplicación de esa ley por los municipios provocó aversión, zozobra y de alguna manera, una protesta silenciosa entre varones considerados aptos para el servicio y sin temor a equivocarnos, esta coyuntura social constituyó un precedente en la mentalidad de aquellos individuos para ir en contra de las normas oficiales instituidas durante ese espacio temporal.

La aplicación de esa ley estuvo vigente durante los años cuarenta del siglo XIX y se mantuvieron las mismas prácticas de reclutamiento y estrés colectivo en la población masculina que se negaba a cumplir esa normativa. Como consecuencia de ese fenómeno, las autoridades locales que cumplieron sus funciones en los pueblos y ciudades donde fueron elegidos no les quedó otra opción que adoptar otro tipo de medidas coercitivas para hacer cumplir esa ley, una de ellas fue allanar el interior de casas y haciendas para llevarse a la fuerza a los individuos. Un ejemplo claro de este tipo de práctica fue lo sucedido en la ciudad de Cuenca, el 2 de julio de 1842, cuando el gobernador de ese poblado capturó a desertores y milicianos que se negaban a recibir la notificación de que fueron seleccionados e inmediatamente fueron puestos a disposición de las autoridades para su traslado hacia los lugares donde fueron requeridos ${ }^{11}$. Con respecto a las fuentes que den cuenta del número de los individuos de tropa que engrosaron las filas del Ejército Permanente contamos con las listas de revista de comisario, registros en los cuales constan en número de individuos de tropa, sin embargo, estos documentos no registran información de cómo fueron enganchados ${ }^{12}$. Desafortunadamente, no se ha logrado ubicar los libros elaborados por los Consejos Municipales que indiquen los registros de los individuos reclutados a través del sistema del sorteo.

11 ANE/Q, 9 de marzo de 1842, Copiador de comunicaciones con la Gobernación de la Provincia de Cuenca que da principio el dia 2 del mes de julio del año de 1840. Transcribiendo una nota del Ministerio de Guerra y Marina, resuelve cuatro puntos relativos al aumento del ejército: si para esto debe aumentar la edad de 18 a 40 años de edad: si para aprehender a los desertores tendrá lugar el alcanzamiento de sus casas: y si solicitando al Colegio formar una compañia separada con dependencia del Jefe del Batallon de Milicias, se podrá acceder a ello, Fondo Presidencia de Quito, Serie Copiadores, Caja 25, 1840-1842, Libro 94, s.f., Documento 54.

12 Las listas de revista de comisario consultadas para el presente trabajo reposan en el Archivo del Centro de Estudios Históricos del Ejército Ecuatoriano con sede en la ciudad de Quito y en el Fondo Especial del Archivo Histórico Nacional de Ecuador. 
Revista de Humanidades, 43 (2021). p. 149-173. ISSN 1130-5029

Guadro N.- 1 DESERTORES, MUERTOS Y DESAPARECIDOS

\begin{tabular}{|c|c|c|c|c|}
\hline Año & Desertores & Muertos & Desaparecidos & Total \\
\hline \multirow{2}{*}{1835} & 41 & 13 & 0 & 54 \\
\hline & $75,93 \%$ & $24,07 \%$ & $0,00 \%$ & $100,00 \%$ \\
\hline \multirow{2}{*}{1836} & 7 & 1 & 0 & 8 \\
\hline & $87,50 \%$ & $12,50 \%$ & $0,00 \%$ & $100,00 \%$ \\
\hline \multirow{2}{*}{1837} & 44 & 2 & 0 & 46 \\
\hline & $95,65 \%$ & $4,35 \%$ & $0,00 \%$ & $100,00 \%$ \\
\hline \multirow{2}{*}{1838} & 28 & 4 & 0 & 32 \\
\hline & $87,50 \%$ & $12,50 \%$ & $0,00 \%$ & $100,00 \%$ \\
\hline \multirow{2}{*}{1839} & 19 & 2 & 0 & 21 \\
\hline & $90,48 \%$ & $9,52 \%$ & $0,00 \%$ & $100,00 \%$ \\
\hline \multirow{2}{*}{1840} & 52 & 4 & 0 & 56 \\
\hline & $92,86 \%$ & $7,14 \%$ & $0,00 \%$ & $100,00 \%$ \\
\hline \multirow{2}{*}{1841} & 17 & 5 & 0 & 22 \\
\hline & $77,27 \%$ & $22,73 \%$ & $0,00 \%$ & $100,00 \%$ \\
\hline \multirow{2}{*}{1842} & 11 & 2 & 0 & 13 \\
\hline & $84,62 \%$ & $15,38 \%$ & $0,00 \%$ & $100,00 \%$ \\
\hline \multirow{2}{*}{1844} & 12 & 1 & 0 & 13 \\
\hline & $92,31 \%$ & $7,69 \%$ & $0,00 \%$ & $100,00 \%$ \\
\hline \multirow{2}{*}{1845} & 2 & 1 & 0 & 3 \\
\hline & $66,67 \%$ & $33,33 \%$ & $0,00 \%$ & $100,00 \%$ \\
\hline \multirow{2}{*}{1850} & 10 & 0 & 0 & 10 \\
\hline & $100,00 \%$ & $0,00 \%$ & $0,00 \%$ & $100,00 \%$ \\
\hline \multirow{2}{*}{1860} & 75 & 14 & 1 & 90 \\
\hline & $83,33 \%$ & $15,56 \%$ & $1,11 \%$ & $100,00 \%$ \\
\hline \multirow{2}{*}{ Total } & 318 & 49 & 1 & 368 \\
\hline & $86,41 \%$ & $13,32 \%$ & $0,27 \%$ & $100,00 \%$ \\
\hline
\end{tabular}

Elaborado por: Cristian Espinel López y Marisol Aguilar Echeverría

Fuentes: AH-CEHE/P, [Lista para pasar revista de comisario en el mes de la fecha], Fondo Revista de

Comisario, Caja 70, RC0275-RC0278/ RC00278/035, 1835-1837/Regimiento de Lanceros del Ecuador 2, f.

$1-258$.

AH-CEHE/P, [Lista para pasar revista de comisario en el mes de la fecha], Fondo Revista de Comisario, Caja

71, RC0279-RC0282/035, 1835-1837/Regimiento de Lanceros del Ecuador 2, f. 8-136.

AH-CEHE/P, [Lista para pasar revista de comisario en el mes de la fecha], Fondo Revista de Comisario,

RC0280/Regimiento de Lanceros 2 de la Guardia, 037/1840-1844, f. 8-136.

ANE/Q, Fondo Especial, Caja 297, 1839, vol. 733, f. 54-63.

ANE/Q, Fondo Especial, Caja 337, 1849-1850, vol. 860, f. 213.

ANE/Q, Fondo Ministerio del Interior, Gobernación de la Provincia de Pichincha, Caja 13, 1844, s.f.

ANE/Q, Fondo Ministerio del Interior, Gobernación de la Provincia de Chimborazo, Caja 3, 1843-1845, s.f. 
El papel desempeñado por los concejos municipales... - M. Aguilar Echevarría

Guadro N.- 2 DESERTORES, MUERTOS Y DESAPARECIDOS Crecimiento/ Decrecimiento Total Año a Año

\begin{tabular}{ll|l}
$1835-1860$ & Total por año & Crecimiento/Decrecimiento año a año \\
\hline Año & 54 & $-85,19 \%$ \\
\hline 1835 & 8 & $475,00 \%$ \\
\hline 1836 & 46 & $-30,43 \%$ \\
\hline 1837 & 32 & $-34,38 \%$ \\
\hline 1838 & 21 & $166,67 \%$ \\
\hline 1839 & 56 & $-60,71 \%$ \\
\hline 1841 & 22 & $-40,91 \%$ \\
\hline 1842 & 13 & $0,00 \%$ \\
\hline 1844 & 13 & $-76,92 \%$ \\
\hline 1845 & 3 & $233,33 \%$ \\
\hline 1850 & 10 & $800,00 \%$ \\
\hline 1860 & 90 & \\
\hline Total & 368 & \\
\hline
\end{tabular}

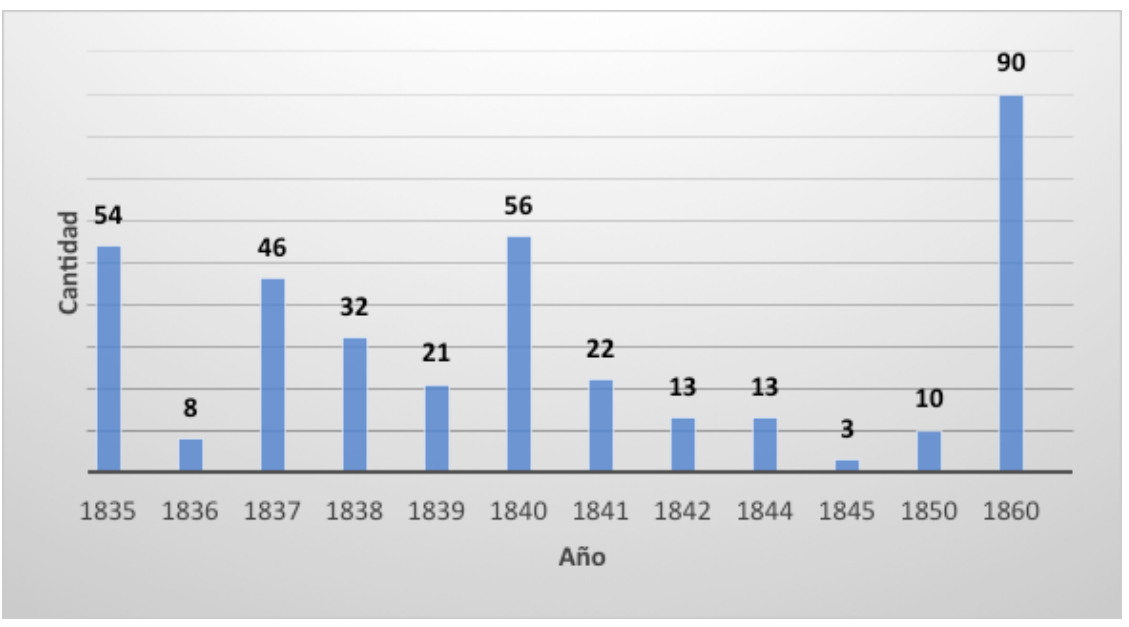

Elaborado por: Cristian Espinel López y Marisol Aguilar Echeverría

Fuentes: AH-CEHE/P, [Lista para pasar revista de comisario en el mes de la fecha], Fondo Revista de Comisario, Caja 70, RC0275-RC0278/ RC00278/035, 1835-1837/Regimiento de Lanceros del Ecuador 2, f. 1-258.

AH-CEHE/P, [Lista para pasar revista de comisario en el mes de la fecha], Fondo Revista de Comisario, Caja 71, RC0279-RC0282/035, 1835-1837/Regimiento de Lanceros del Ecuador 2, f. 8-136.

AH-CEHE/P, [Lista para pasar revista de comisario en el mes de la fecha], Fondo Revista de Comisario, RC0280/ Regimiento de Lanceros 2 de la Guardia, 037/1840-1844, f. 8-136.

ANE/Q, Fondo Especial, Caja 297, 1839, vol. 733, f. 54-63.

ANE/Q, Fondo Especial, Caja 337, 1849-1850, vol. 860, f. 213.

ANE/Q, Fondo Ministerio del Interior, Gobernación de la Provincia de Pichincha, Caja 13, 1844, s.f.

ANE/Q, Fondo Ministerio del Interior, Gobernación de la Provincia de Chimborazo, Caja 3, 1843-1845, s.f 
Cuadro N.- 3 DESERTORES MUERTOS Y DESAPARECIDOS. Peso porcentual de la Tropa por rango

1841-1858

\begin{tabular}{lll}
\hline Rango & Total & Peso porcentual por rango \\
\hline Desertores & 318 & $86,41 \%$ \\
\hline Muertos & 49 & $13,32 \%$ \\
\hline Desaparecidos & 1 & $0,27 \%$ \\
\hline Total & 368 & $100,00 \%$ \\
\hline
\end{tabular}

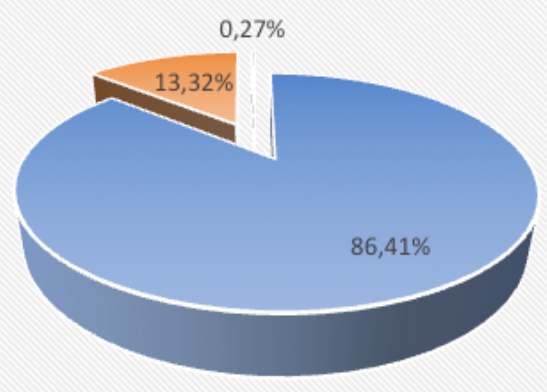

Elaborado por: Cristian Espinel López y Marisol Aguilar Echeverría

Fuentes: AH-CEHE/P, [Lista para pasar revista de comisario en el mes de la fecha], Fondo Revista de

Comisario, Caja 70, RC0275-RC0278/ RC00278/035, 1835-1837/Regimiento de Lanceros del Ecuador 2, f.

$1-258$.

AH-CEHE/P, [Lista para pasar revista de comisario en el mes de la fecha], Fondo Revista de Comisario, Caja 71, RC0279-RC0282/035, 1835-1837/Regimiento de Lanceros del Ecuador 2, f. 8-136.

AH-CEHE/P, [Lista para pasar revista de comisario en el mes de la fecha], Fondo Revista de Comisario, RC0280/Regimiento de Lanceros 2 de la Guardia, 037/1840-1844, f. 8-136.

ANE/Q, Fondo Especial, Caja 297, 1839, vol. 733, f. 54-63.

ANE/Q, Fondo Especial, Caja 337, 1849-1850, vol. 860, f. 213.

ANE/Q, Fondo Ministerio del Interior, Gobernación de la Provincia de Pichincha, Caja 13, 1844, s.f.

ANE/Q, Fondo Ministerio del Interior, Gobernación de la Provincia de Chimborazo, Caja 3, 1843-1845, s.f.

En el caso del reemplazo, la Ley de Conscripción del Ejército de 1837 estableció ese sistema como una "opción" a la que podía acogerse el sorteado en caso de que fuera seleccionado. La alternativa puesta a consideración del individuo seleccionado conllevó a que este pueda desvincularse del sistema del sorteo siempre y cuando esté presente un reemplazo o en su lugar, pagar veinte pesos para enganchar a otro sujeto. Este sistema era funcional para aquellos individuos que podían pagar esa suma de dinero y así, exonerarse de manera legal de cumplir el servicio. Por otro lado, la mencionada ley también estipulaba que los individuos podían presentarse de manera voluntaria, sin embargo, no se ha hallado evidencia empírica que dé cuenta de cuántos individuos se enrolaron bajo esta condición. A pesar de no contar con información de sujetos que se presentaron voluntariamente en las filas militares, 
esta "opción" implicaba que los individuos enrolados bajo esa modalidad debieran cumplir una serie de exigencias tales como: no tener un proceso criminal en curso, elegir el arma o especialidad a la que desean ser destinados, esta última opción estaba sujeta a las habilidades que demuestre el voluntario para cumplir a cabalidad el servicio. Adicionalmente, aquella normativa también determinaba la estatura del individuo que debió cumplir el estándar de cinco pies.

A pesar de que la ley que es objeto de análisis determinó que ningún enrolado estuvo obligado a cumplir el servicio por más tiempo en esa normativa, se puede especular que, en la práctica, existió un déficit de individuos que acudan de manera espontánea a cumplir el servicio militar. De todos modos, tras el análisis de la documentación consultada para este trabajo deja constancia que los individuos que fueron reclutados ya sean de manera forzada o voluntaria, permanecieron más tiempo de lo previsto y se acostumbraron a llevar ese modo de vida.

Aquella normativa expedida durante el año de 1837 fue reformada el 21 de octubre de 1854 durante la presidencia del General José María Urbina. Entre las modificaciones realizadas a esa la ley de 1837 fue la orden dada al cuerpo de policía para que capture a los vagabundos y a los sorteados que se negaron a cumplir el servicio para que sirvan en las filas del Ejército Permanente ${ }^{13}$. Adicionalmente, esa ley incorporó la salvedad de no registrar en el servicio militar a aquellos sorteados que se encontraban fuera del país; en ese caso, los representantes de los Concejos Municipales seleccionaban en su lugar a otros ciudadanos para que ocupen el lugar de aquellos que se encontraban ausentes.

Seguramente, ese procedimiento fue consecuencia de la ausencia de individuos que fueron desterrados por simpatizar a la causa de gobiernos anteriores, pero por otro, era un mecanismo disfuncional que recayó de manera negativa en aquellos sujetos que ya cumplieron más allá del tiempo del servicio y, en consecuencia, eso creó malestar entre los pobladores de pueblos y ciudades donde se efectuó el reclutamiento de soldados. Para evitar las supuestas inconformidades entre la gente, aquella normativa contempló en el artículo 16 que, en caso de que las autoridades locales excluyeran al individuo que fue sorteado y puesto en su lugar a otro sujeto que no fue seleccionado, el agraviado tenía la potestad de presentar un reclamo por escrito al gobierno y si esa petición resultaba favorable al perjudicado, el funcionario responsable del proceso de recluta era sancionado con una multa de veinticinco a doscientos pesos, fondos que fueron destinados a los caudales de manumisión de los esclavos.

13 ANE/Q, Quito, 21 de octubre de 1854, Decreto Legislativo expedido por el senado en el que dictamina la conscripción y el sorteo de los soldados del ejército, Fondo Especial, caja 350, 1854, vol. 916, fs. 132-135. 


\subsection{Labor de las fuerzas militares en el interior de las ciudades}

Durante los primeros treinta años de Ecuador como estado independiente, las fuerzas militares encargadas de la vigilancia de las ciudades fueron denominadas milicias urbanas o Guardia Nacional. Las milicias urbanas fueron formaciones de vecinos conformados por varones entre los dieciséis hasta los sesenta años con excepción de los eclesiásticos regulares y seculares, indígenas tributarios, esclavos y aquellos sujetos con enfermedades que les imposibiliten cumplir con el servicio ${ }^{14}$. La Guardia Nacional en cambio consistió en la organización armada conformada todos los empleados civiles y de hacienda, los comerciantes, los propietarios y artesanos afiliados a gremios ${ }^{15}$. En el marco de esta definición, las diversas formaciones militares de este tipo tuvieron su proceso de surgimiento, vigencia y desaparición de acuerdo con las circunstancias que afrontaron en esos momentos. Los únicos registros con los que contamos para la tabulación del número de individuos que integraron estas formaciones militares son los informes anuales emitidos por el Ministerio de Guerra y Marina y de algunos documentos dispersos que reposan en el Fondo Especial del Archivo Histórico Nacional de Ecuador.

\section{Guadro N.- 4. TROPA MILITAR AUXILIAR}

$1847-1848$

\begin{tabular}{cccccccc}
\hline Año & $\begin{array}{c}\text { Sargentos } \\
\text { primeros }\end{array}$ & $\begin{array}{c}\text { Sargentos } \\
\text { segundos }\end{array}$ & $\begin{array}{c}\text { Cabos } \\
\text { Primeros }\end{array}$ & $\begin{array}{c}\text { Cabos } \\
\text { segundos }\end{array}$ & $\begin{array}{c}\text { Banda de música } \\
\text { (trompetas, cornetas y } \\
\text { tambores) }\end{array}$ & Soldados & TOTAL \\
\hline \multirow{2}{*}{1847} & 10 & 18 & 18 & 0 & 31 & 123 & 200 \\
\cline { 2 - 8 } & $5,00 \%$ & $9,00 \%$ & $9,00 \%$ & $0,00 \%$ & $15,50 \%$ & $61,50 \%$ & $100,00 \%$ \\
\hline \multirow{2}{*}{ Total } & 10 & 36 & 74 & 70 & 68 & 660 & 918 \\
\cline { 2 - 9 } & $1,09 \%$ & $3,92 \%$ & $8,06 \%$ & $7,63 \%$ & $7,41 \%$ & $71,90 \%$ & $100,00 \%$ \\
\hline
\end{tabular}

Elaborado por: Cristian Espinel López y Marisol Aguilar Echeverría

Fuentes: AH-CEHE/P, Fondo Revista de Comisario, caja no 91/rc-0001/rc-0004, RC-00367/008, 1835-1863, f.

1-32. ANE/Q, Fondo Ministerio del Interior/Gobernación del Guayas, Caja 15, 1859-1860, s.f.

14 Exposición que dirige al Congreso Constitucional del Ecuador en 1847 el Secretario de Guerra y Marina, Oficina de Joaquín Terán, Quito, p. 10.

15 ANE/Q, Quito, 28 de agosto de 1843, [Comunicación del Ministro de Hacienda, Francisco de Aguirre al Gobernador de la Provincia de Pichincha en el que informa las medidas tomadas para asegurar el orden y la seguridad de los tumultos experimentados en la capital de la República], Fondo Especial, caja 313, 1843, vol. 781, fs. 374-375. 
Cuadro N.- 5. TROPA MILITAR AUXILIAR. Crecimiento/ Decrecimiento Año a Año

\begin{tabular}{|c|c|c|}
\hline Año & Total por año & Crecimiento/Decrecimiento año a año \\
\hline 1847 & 200 & \\
\hline 1848 & 918 & $359,00 \%$ \\
\hline Total & 1.118 & \\
\hline
\end{tabular}

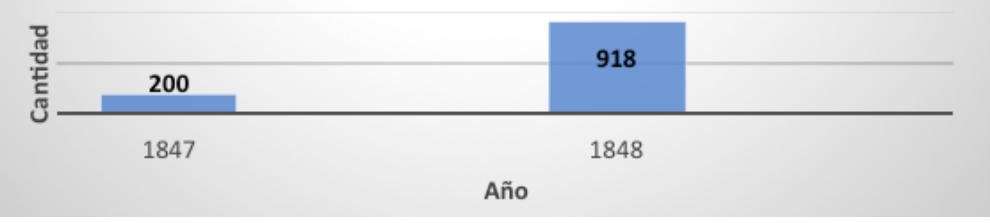

Elaborado por: Cristian Espinel López y Marisol Aguilar Echeverría

Fuentes: AH-CEHE/P, Fondo Revista de Comisario, caja no 91/rc-0001/rc-0004, RC-00367/008, 1835-1863, f.

1-32. ANE/Q, Fondo Ministerio del Interior/Gobernación del Guayas, Caja 15, 1859-1860, s.f.

Cuadro N.- 6. TROPA MILITAR AUXILIAR. Peso porcentual por rango 1847-1848

\begin{tabular}{lcc}
\hline Rango & Total & Peso porcentual por rango \\
\hline Sargentos primeros & 20 & $1,79 \%$ \\
\hline Sargentos segundos & 54 & $4,83 \%$ \\
\hline Cabos Primeros & 92 & $8,23 \%$ \\
\hline Cabos segundos & 70 & $6,26 \%$ \\
\hline Banda de música (trompetas, cornetas y tambores) & 99 & $8,86 \%$ \\
\hline Soldados & 783 & $70,04 \%$ \\
\hline TOTAL & 1.118 & $100,00 \%$ \\
\hline
\end{tabular}

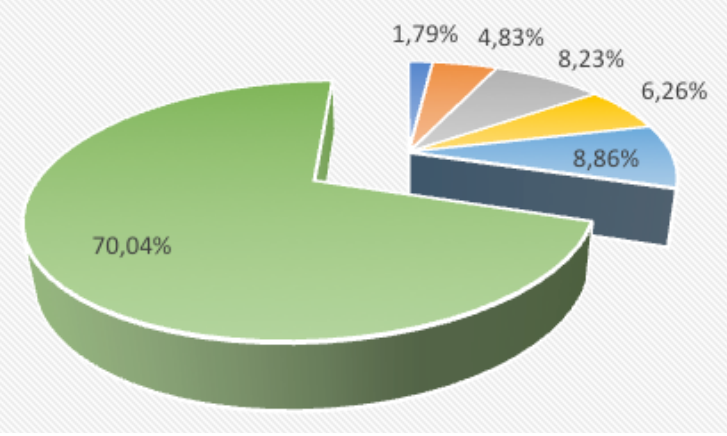

Elaborado por: Cristian Espinel López y Marisol Aguilar Echeverría

Fuentes: AH-CEHE/P, Fondo Revista de Comisario, caja no 91/rc-0001/rc-0004, RC-00367/008, 1835-1863, f.

1-32. ANE/Q, Fondo Ministerio del Interior/Gobernación del Guayas, Caja 15, 1859-1860, s.f. 
Revista de Humanidades, 43 (2021). p. 149-173. ISSN 1130-5029

Guadro N.- 7. TROPA GUARDIA NACIONAL

$1846-1858$

\begin{tabular}{cccccccc}
\hline \multirow{2}{*}{ Año } & $\begin{array}{c}\text { Sargentos } \\
\text { primeros }\end{array}$ & $\begin{array}{c}\text { Sargentos } \\
\text { segundos }\end{array}$ & $\begin{array}{c}\text { Cabos } \\
\text { Primeros }\end{array}$ & $\begin{array}{c}\text { Cabos } \\
\text { segundos }\end{array}$ & $\begin{array}{c}\text { Banda de música } \\
\text { (trompetas, } \\
\text { cornetas y } \\
\text { tambores) }\end{array}$ & Soldados & TOTAL \\
\hline \multirow{2}{*}{1846} & 282 & 551 & 614 & 626 & 184 & 10031 & 12.288 \\
\cline { 2 - 9 } & $2,29 \%$ & $4,48 \%$ & $5,00 \%$ & $5,09 \%$ & $1,50 \%$ & $81,63 \%$ & $100,00 \%$ \\
\hline \multirow{2}{*}{1847} & 367 & 628 & 740 & 806 & 142 & 10229 & 12.912 \\
\cline { 2 - 9 } & $2,84 \%$ & $4,86 \%$ & $5,73 \%$ & $6,24 \%$ & $1,10 \%$ & $79,22 \%$ & $100,00 \%$ \\
\hline \multirow{2}{*}{1856} & 288 & 811 & 849 & 817 & 178 & 13961 & 16.904 \\
\cline { 2 - 9 } & $1,70 \%$ & $4,80 \%$ & $5,02 \%$ & $4,83 \%$ & $1,05 \%$ & $82,59 \%$ & $100,00 \%$ \\
\hline \multirow{2}{*}{1857} & 228 & 811 & 849 & 817 & 178 & 13961 & 16.844 \\
\cline { 2 - 9 } & $1,35 \%$ & $4,81 \%$ & $5,04 \%$ & $4,85 \%$ & $1,06 \%$ & $82,88 \%$ & $100,00 \%$ \\
\hline \multirow{2}{*}{1858} & 281 & 819 & 856 & 832 & 171 & 14497 & 17.456 \\
\cline { 2 - 9 } Total & $1,61 \%$ & $4,69 \%$ & $4,90 \%$ & $4,77 \%$ & $0,98 \%$ & $83,05 \%$ & $100,00 \%$ \\
\cline { 2 - 8 } & 1.446 & 3.620 & 3.908 & 3.898 & 853 & 62.679 & 76.404 \\
\hline
\end{tabular}

Elaborado por: Cristian Espinel López y Marisol Aguilar Echeverría

Fuentes: Memorias Ministerio de Guerra y Marina

Una de las formaciones armadas de este tipo que existieron a inicios del periodo republicano fue la Milicia Protectora de la Capital de la República, cuerpo militar establecido por decreto ejecutivo expedido el 14 de octubre de $1831^{16}$. Aquel reglamento indicó de manera detallada la organización de los vecinos de Quito en barrios y manzanas en las cuales debieron nombrarse responsables de cada uno de esos segmentos urbanos, estos fueron: jefes de barrio y los jefes de manzanas, estas dos autoridades fueron nombrados delegados del gobierno central y cumplieron las funciones de transmitir órdenes directas del poder ejecutivo. Asimismo, esa normativa apuntó que los jefes de manzanas tuvieron el rango de capitanes a partir del momento de su nombramiento y contaba con la ayuda de un asistente de confianza para hacer posible la ejecución de las órdenes dispuestas por el jefe de barrio.

Los jefes de manzana fueron los encargados de redactar listas con los nombres y apellidos de los propietarios varones entre los catorce hasta los cincuenta años, quienes desempeñaron algún de tipo de industria u oficio y que disfrutaban de una

16 ANE/Q, Quito, 14 de octubre de 1831, [Reglamento Provisional para la organización de la milicia protectora de la capital], Fondo Especial, caja 270, 1831, vol. 668, fs. 165-166. 
El papel desempeñado por los concejos municipales... - M. Aguilar Echevarría

Cuadro N.- 8. TROPA GUARDIA NACIONAL. Crecimiento/ Decrecimiento Año a Año

\begin{tabular}{cc|c}
$1846-1858$ & Total por año & \multirow{2}{*}{ Crecimiento/Decrecimiento año a año } \\
\hline Año & 12.288 & \\
\hline 1846 & 12.912 & $5,08 \%$ \\
\hline 1847 & 16.904 & $30,92 \%$ \\
\hline 1856 & 16.844 & $-0,35 \%$ \\
\hline 1857 & 17.456 & $3,63 \%$ \\
\hline 1858 & 76.404 & \\
\hline Total & & \\
\hline
\end{tabular}

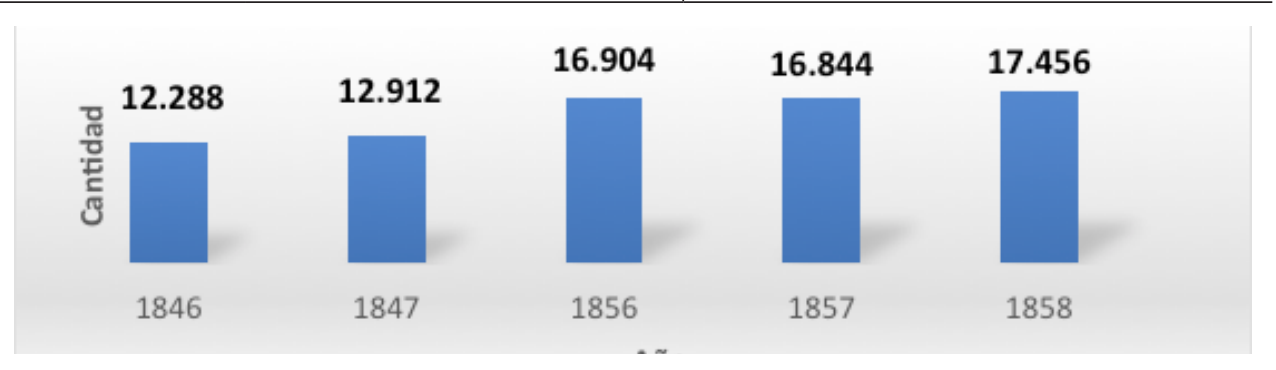

Elaborado por: Cristian Espinel López y Marisol Aguilar Echeverría

Fuentes: Memorias Ministerio de Guerra y Marina

renta anual de 4000 pesos. Aquellas listas fueron entregadas a los jefes de barrio quienes seleccionaban a los vecinos para que integren ese cuerpo de milicia.

Luego de cumplido ese proceso, los jefes de barrio estaban en la obligación de reunir a los individuos escogidos para orientarles en la cuestión de velar por la seguridad del bien público y de sus propiedades para así, evitar actos vandálicos perpetrado caudillos desafectos hacia el mandatario de turno. El paso siguiente fue pedir a los vecinos convocados organizar una especie de compañía que estuvo conformada por individuos de confianza del jefe de barrio.

Como el estado no estaba en la capacidad financiera de solventar la dotación de armamento para estas formaciones castrenses aquella normativa contempló que el apertrechamiento de armas estuviera a cargo de los propietarios que organizaron esos cuerpos militares quienes fueron responsables de la reposición de aquellos objetos en caso de pérdida o daño a pesar de que ellos dotaban con su dinero de esos elementos.

Es necesario enfatizar que ese tipo de formación armada no estuvo liderada directamente por las autoridades locales a pesar que el alistamiento de soldados se hicieron en las casas y lugares públicos de las ciudades y como se expresó en la 


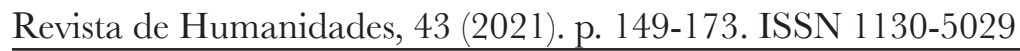

Cuadro N.- 9. TROPA GUARDIA NACIONAL. Peso porcentual por rango

\begin{tabular}{lcc}
\hline Rango & & \\
\hline Sargentos primeros & Total & Peso porcentual por rango \\
\hline Sargentos segundos & 1.446 & $1,89 \%$ \\
\hline Cabos Primeros & 3.620 & $4,74 \%$ \\
\hline Cabos segundos & 3.908 & $5,11 \%$ \\
\hline Banda de música (trompetas, cornetas y tambores) & 3.898 & $5,10 \%$ \\
\hline Soldados & 853 & $1,12 \%$ \\
\hline TOTAL & 62.679 & $82,04 \%$ \\
\hline & & \\
\hline
\end{tabular}

Elaborado por: Cristian Espinel López y Marisol Aguilar Echeverría

Fuentes: Memorias Ministerio de Guerra y Marina

primera parte de este trabajo, los prefectos, corregidores, alcaldes, tenientes políticos y demás autoridades que cumplieron sus funciones en la esfera local no tuvieron responsabilidad directa en los aspectos legales y financieros de la jurisdicción que gobernaban. En el caso que es objeto el presente análisis estas formaciones militares civiles fueron lideradas por el Jefe de Gobierno quien fue la máxima autoridad de la Milicia Protectora de Quito y las órdenes dispuestas para este cuerpo armado fueron estipuladas por el Estado Mayor General destinado para el efecto.

Retomando lo estipulado en la normativa de la Milicia Protectora de Quito, las señales ensayadas por las autoridades para reunir a este cuerpo militar al momento de una invasión o ataque de tropas irregulares fueron: un tiro de cañón disparado desde cualquier punto de la ciudad; en caso de que el disparo del cañón no se realizaba, los empleados de las iglesias iban hacia las torres para tocar las campañas, señal que conocieron los milicianos de antemano, luego de dada esa señal, los milicianos se agrupaban con sus demás compañeros y se dirigían inmediatamente hacia el lugar que les indicaba los jefes de manzana para luego ser conducidos a la plaza principal para reunirse con los demás individuos procedentes de los demás barrios a la espera de órdenes del Jefe de Gobierno. 
Aquel reglamento también consideró sanciones para quien se rehúse a cumplir el servicio o ignoren las señales de alarma, estas fueron: multa para los jefes de barrio y a aquellos jefes de manzana que no acataban las órdenes establecidas. En el caso de los sirvientes que se resistieron a obedecer y colaborar con los jefes de barrio y manzana se los enrolaba automáticamente a las filas el Ejército Permanente. Esta norma también fue aplicada para aquellos individuos que se rehusaron a presentarse al llamado de los jefes de barrio en el momento del alistamiento.

Este tipo de incorporación eximió a los individuos que sirvieron en la Milicia Protectora de Quito para servir en las filas del Ejército Permanente en caso de que fuesen sorteados. Por otro lado, los jefes de barrio tuvieron la responsabilidad de pasar revista o supervisar a los jefes de manzana quienes debieron entrenar a los milicianos en fecha establecida por aquellos dirigentes. La vigencia de aquella normativa permitió de alguna manera a la ciudad de Quito estar protegida de los ataques de los opositores del gobierno del General Juan José Flores y esto fue posible gracias a la colaboración de los vecinos quienes apoyaron a la labor de la guardia policial que estuvo encargada de vigilar y controlar la seguridad pública de los habitantes de la capital de la República.

En 1835, la Convención Nacional de Ambato hizo algunas reformas al reglamento de milicia que tuvo vigencia desde 1826 y en esa normativa cambió la denominación de Milicia Auxiliar a Milicia Nacional. Aquella ordenanza dictaminó que todo varón desde los dieciocho hasta los cuarenta años sea alistado en esa formación militar. Las armas o especialidades en los que los soldados ejercieron el servicio militar fueron de infantería y caballería. El registro y control de todos los individuos que figuraban en esas formaciones estuvo a cargo de los alcaldes parroquiales y corregidores quienes cumplieron la misión de que ningún individuo se encuentre sin prestar el servicio militar.

La responsabilidad de la organización de esos cuerpos armados fue del Comandante de Armas de la Provincia, quien constituyó compañías (en el contexto militar) de ochenta a ciento veinte individuos en base a las listas remitidas por el corregidor de cada cantón. Cada compañía estuvo conformada por los siguientes cargos: un capitán, un teniente primero, un teniente segundo, un subteniente primero, un subteniente segundo, un sargento primero, cuatro sargentos segundos, seis cabos primeros, seis cabos segundos y cuatro tambores o cornetas. De tres a cinco compañías formaban medio batallón y el comandante de esta fue el capitán más antiguo, mientras que la plana mayor estuvo conformada por: un teniente, un sargento y un cabo corneta o tambor. De seis a diez compañías se formaba un batallón que estuvo dirigido por un comandante y la plana mayor estuvo conformada por: un comandante, un segundo comandante, un ayudante mayor, un primer teniente con grado de capitán, un segundo ayudante teniente, dos abanderados subtenientes, un sargento primero tambor, un sargento primero, un cabo primero de brigada y un cabo primero tambor o corneta. 
El Poder Ejecutivo tuvo entre sus atribuciones la formación o desaparición de los escuadrones de caballería en los cantones de la República y cada compañía estuvo dirigida por un capitán, ayudado por: dos tenientes, dos alféreces, un sargento primero, tres segundos, cuatro cabos primeros y cuatro segundos, uno o dos clarines y sesenta o setenta soldados. El capitán de cada compañía estuvo encargado de todo el movimiento económico y logístico que demandada ese tipo de formación. La designación de oficiales que lideraron esos cuerpos de milicia estuvo a cargo de los gobernadores y corregidores quienes mocionaban nombres para que sean ratificados y posesionados por el Presidente de la República o alguna autoridad del Poder Ejecutivo otorguen su nombramiento.

A pesar de la puesta en vigencia de ese reglamento que facilitaría la labor de los alcaldes y corregidores para cumplir con el número de individuos estipulado en esa ordenanza, las autoridades locales enfrentaron la realidad de no reunir a todos los sujetos requeridos que estipulaba esa norma debido a los altos índices de deserción existentes a lo largo de la república.

Dos años después a la formación de ese estatuto, se expidió un nuevo reglamento en el que se arreglaba la Milicia Auxiliar de República. Aquella norma fue expedida el 8 de abril de 1837 la cual fue firmada por el General Juan José Flores quien en ese año fue Presidente del Senado y Vicente Rocafuerte, Presidente de la República. Ese documento compuesto por ocho artículos indicaba la existencia de treinta y seis batallones en los tres distritos militares y una brigada de artillería en la capital de la república. Cada batallón estuvo formado por seis compañías y cada una de ellas estuvo al mando un capitán, dos tenientes, dos subtenientes, un sargento primero, dos sargentos segundos, cuatro cabos primeros, cuatro cabos segundos y un furriel a elección del capitán. La plana mayor de ese cuerpo de milicia estuvo compuesta por un comandante y un capitán que era ayudante del comandante. Todos estos individuos fueron oficiales activos del Ejército Permanente o fuerza veterana que estuvieron vinculados a las élites.

Por otro lado, era frecuente el fenómeno de deserción y fuga de los individuos que se negaron a integrar las filas castrenses, situación que dificultó la estructuración de esos cuerpos armados; a pesar de que las autoridades locales no lograron controlar esa dinámica social, los alcaldes y corregidores adoptaron sendas medidas para reducir el número de desertores a nivel nacional. Un ejemplo de ese tipo de práctica fue en la provincia de Pichincha, cuando el Gobernador de la Provincia ordenó en abril de 1845 que todos vecinos, propietarios y sirvientes que gocen de la confianza de las autoridades se encarguen del arreglo de milicias en las parroquias aledañas a la ciudad de Quito ${ }^{17}$. Para cumplir ese propósito, el Gobernador dio su autorización

17 ANE/Q, Quito, 21 de abril de 1845, [Comunicación del Ministro de Gobierno, Benigno Malo, al Gobernador de la Provincia de Pichincha en el que informa que el Encargado del Poder Ejecutivo ha dispuesto la organización de milicias nacionales en las parroquias aledañas a la ciudad de Quito con el 
para que vecinos de "buenas familias" atrapen a vagos y desertores para formar esos cuerpos de milicia.

En la ciudad de Guayaquil, en cambio, se establecieron tres tipos de milicia durante ese año con el fin de resguardar la seguridad de la ciudad: estas milicias fueron: Comercio, Bombas y Guardia Nacional. La Comandancia General del Distrito de esa provincia estuvo a cargo de esos tres cuerpos y entre sus atribuciones fue ordenar a los jefes del ejército designados para esa función cumplan con la instrucción, arreglo y disciplina de esos cuerpos de milicias. Las actividades realizadas por esas formaciones militares se concretaron en hacer guardias de prevención, patrullas y ejercicios doctrinales de dos horas diarias. Las compañías de Comercio y de Bombas realizaban guardias en grupos de veinte individuos y los milicianos de la Compañía de Comercio se acuartelaron en el Juzgado de Comercio de esa ciudad. Los individuos que estuvieron exentos de cumplir del servicio de milicia en Guayaquil fueron: los empleados de la administración pública, amanuenses, porteros, directores e institutores de las escuelas públicas y la cuadrilla de la Aduana.

En el caso de la ciudad de Quito, ese cuerpo militar fue organizado siete años antes. El Juzgado de Comercio de la capital en 1838 dispuso que el gremio de comerciantes acuartele a sus socios para que hagan rondas en la capital de la república. Aquella disposición fue también emitida para el gremio de músicos y subalternos para que se sumen al servicio de patrullas de prevención. En septiembre de 1840, el vicepresidente de la República dispuso la organización de dos compañías de Guardia Nacional compuesta por los comerciantes de Quito. El arreglo de los cuerpos de milicia de: comerciantes, músicos y subalternos estuvieron a cargo del Corregidor del cantón. Las labores de vigilancia asignadas al gremio de músicos fueron dictaminadas a través de la emisión de boletas de seguridad otorgadas por el Comisario General de Policía y aquellas papeletas iban a ser entregadas al maestro mayor de ese gremio luego de organizada la compañía de milicias de esa corporación artesanal. Luego de organizados esos cuerpos de milicia, los enlistados realizaron guardias en grupos para que vigilen la cárcel, el hospital y otros lugares que necesitaban ser resguardados. La Compañía de Músicos estuvo bajo las órdenes de los jefes de la Compañía de Comercio.

Los miembros que conformaron la milicia de los comerciantes no podían ser enrolada en las filas del Ejército Permanente ni tampoco sancionados penalmente debido a que su oficio fue vital en la generación de recursos económicos a través de sus redes clientelares; en consecuencia, era muy perjudicial para los miembros de ese gremio que uno de sus socios se dedicara a esas labores ya que, en vez de generar progreso personal y de su negocio, su contingente en las filas del Ejército Permanente era penosa e inútil. Ante esta situación, el Gobernador Accidental de la Provincia de Pichincha dispuso que, si no asistían a la hora convocada para organizar

objeto de recoger armas que están en poder de los ciudadanos y capturar a vagos y desertores que no colaboran en el servicio de las armas], Fondo Especial, caja 318, 1845, vol. 801, fs. 166-167 
el cuerpo militar eran sancionados con una multa de cien pesos o arresto de ocho a quince días ${ }^{18}$.

La iniciativa del gobierno para establecer batallones cívicos formados por comerciantes en las ciudades de Quito y Guayaquil tuvo óptimos resultados debido a que los afiliados a ese gremio cumplieron sus funciones sin muchas dificultades y de alguna manera, las ciudades estaban resguardadas gracias a la labor realizada por los comerciantes de ambas ciudades. El modelo de la milicia de los comerciantes fue replicado en la provincia de Chimborazo en el año de 1858 con el propósito de resguardar a la ciudad de Riobamba de los ataques de los indígenas. La misión de ese cuerpo militar fue convencer a los indígenas que depongan su posición belicosa a cambio de ser eximidos del tributo.

\section{GONGLUSIONES}

La revisión de literatura referente a la vinculación entre cabildo y fuerza deja entrever que todavía falta profundizar en: investigación de fuentes, categorías conceptuales, desarrollo de análisis que permitan conocer y tener fundamentos para interpretar la realidad de la municipalidad ecuatoriana a inicios del periodo republicano. En definitiva, nos atrevemos a afirmar que esta temática de estudio es virgen debido a la ausencia de estudios profundos que vinculen la cuestión administrativa y militar con la cotidianidad de los ciudadanos comunes que residieron en las ciudades.

Por otro lado, la diversidad de intereses y planes a futuro ideados por los representantes del poder local provocó que la institución municipal se fragmente y se disperse. Esta coyuntura posibilitó a que las élites y los gobiernos de turno que no coincidan con las agendas de las élites locales se enfrenten de manera constante, a tal punto que, tanto los representantes de las oligarquías y los gobiernos movilicen cada uno por su lado una ingente cantidad de recursos económicos, armas y hombres para hacer frente a las tensiones presentadas entre aquellos bandos. Por otro lado, los representantes de los círculos de poder elegidos constitucionalmente por las instancias legislativas de Ecuador de ese tiempo aprovecharon del débil aparato estatal para que, a través de leyes y reglamentos puedan reclutar individuos para emprender cruzadas belicistas y así, tomar por la vía de las armas lo que, según ellos, era suyo.

Las autoridades locales tuvieron la obligación de ejecutar lo que dictaminaba el gobierno y las instancias legislativas y así, dar cumplimiento a la recluta de individuos

18 ANE/Q, Quito, 22 de marzo de 1848, [Decreto Ejecutivo expedido por el Gobernador de la Provincia de Pichincha, Francisco Javier Villacis y Carcelén en el que dictamina que los comerciantes matriculados formen la compañía que patrulla la ciudad de Quito], Fondo Especial, caja 331, 1848, vol. 837, f. 183. 
para que alimenten la leva del ejército permanente. En este sentido, los gobiernos locales estuvieron facultados para aplicar los mecanismos de: sorteo, remplazo y organización de cuerpos de milicia para cumplir las órdenes directas del poder central para el reclutamiento de soldados. Los decretos y normativas expedidas para reclutar a individuos en condiciones para combatir estipularon métodos poco ortodoxos para la recluta, situación que provocó paranoia colectiva al momento del sorteo solo por el hecho de ser trasladados hacia otros lugares a combatir en contra de su voluntad fue un factor que provocó malestar. Esta situación se evidencia por el alto número de individuos que desertaban de las filas castrenses cuyo registro consta en las listas de revista de comisario que llevaban los oficiales de las unidades militares que se encargaban de esa labor La alternativa del reemplazo, en cambio, fue un recurso utilizado por individuos con suficiente solvencia económica para liberarse de ese compromiso que resquebrajaba su vida normal.

En el caso de los cuerpos de milicia establecidos para el control y protección de las ciudades, esas agrupaciones permitieron que los mismos vecinos sean los encargados de la seguridad de los entornos donde residieron; por lo tanto, los jefes de cada una de las familias más representativas de las ciudades fueron quienes lideraron ese proceso con sus sirvientes y gente de confianza. A pesar de que esa organización de tropas se desenvolvió en esos entornos, los gobiernos locales como tal, desempeñaron exclusivamente las tareas de control de nómina de los vecinos que conformaron esas formaciones castrenses y la institución municipal como tal no tuvo participación legal, administrativa y doctrinaria en este tipo de procesos y solamente se limitaron a cumplir las disposiciones establecidas por el poder ejecutivo.

\section{FUENTES}

\subsection{Primerias}

Archivo Nacional de Ecuador: Fondo Especial.

Archivo Nacional de Ecuador: Fondo Presidencia de Quito, serie: copiadores

Archivo Histórico del Centro de Estudios Históricos del Ejército Ecuatoriano: Fondo Administrativo, Revista de Comisario.

\subsection{Fuentes impresas}

Exposición que dirige al Congreso Constitucional del Ecuador en 1847 el Secretario de Guerra y Marina, Oficina de Joaquín Terán, Quito.

Memoria que dirije al Congreso del Ecuador en 1833 el Jeneral Jefe de Estado Mayor Jeneral sobre los negocios de guerra y marina, Imprenta de Gobierno por Juan Campusano, Quito.

Memoria que el Ministro de Guerra y Marina presenta a la Lejislatura de 1837, Imprenta de gobierno, por Juan Campuzano 


\section{BIBLIOGRAFÍA}

Ayala Mora, E. (2011). Ecuador del siglo XIX. Estado Nacional, Ejército, Iglesia y Municipio. Quito: Universidad Andina Simón Bolívar-Corporación Editora Nacional.

Borrero, A. L. (2015). Cuenca en el siglo XIX: Cabildo, Ayuntamiento y Municipio, el tránsito de la ciudad colonial a la republicana. Aspectos de su historia urbana. Pucará(26), p. 76.

Cabrera Hanna, S. (2 de Abril de 2021). La estructuración del régimen de intendencias en el Distrito del Sur en tres escenarios (1824-1830): Elecciones, administración territorial y justicia. Almanack(27). doi:https://doi.org/10.1590/2236-463327ed 00521

Caño Ortigosa, J. L. (2020). Fuentes primarias para el estudio de las rentas de propios y arbitrios de los municipios indianos. Naveg@mérica. Revista electrónica editada por la Asociación Española de Americanistas.(25), 1-39. Obtenido de http:// revistas.um.es/navegamerica

Georgetown University. (s.f.). Political Database of the Americas. Recuperado el 25 de Abril de 2021, de Republic of Ecuador / Constitution of 1830: https://pdba. georgetown.edu/Constitutions/Ecuador/ecuador30.html

Maiguashca, J. (1994). El proceso de integración nacional en el Ecuador: el rol del poder central, 1830 - 1895. En J. Maiguashca (Ed.), Historia y región en el Ecuador: 1830 - 1960 (págs. 357-359). Corporación Editora Nacional.

Morelli, F. (2003). Entre el Antiguo y el Nuevo Régimen: el triunfo de los cuerpos intermedios: el caso de la Audiencia de Quito, 1765-1830. Historia y política: Ideas, procesos y movimientos sociales(10), 163-189.

Morelli, F. (2011). "Entre confianza y armas". La justicia local en Ecuador del Antiguo Régimen al liberalismo. Revista Complutense de Historia de America (37), 27-47. doi:10.5209/rev_RCHA.2011.v37.2

Prado Arellano, L. E. (2019). La organización de los ejércitos republicanos en la Nueva Granada: Provincias del Cauca (1830-1855). Tesis doctoral. Quito: Universidad Andina Simón Bolivar.

Rodriguez O., J. (2006). La revolución política durante la época de la independencia. El Reino de Quito 1808-1822 (Vol. 20). Quito: Universidad Andina Simón BolívarCorporación Editora Nacional. 
